DOI: 10.1590/permusi2015a3108

\title{
Avaliação da performance instrumental pelos professores de trompete: questões e desafios
}

Maria Clara Costa (Esc. Superior de Educação de Fafe; Esc. Superior de Tecnologias de Saúde do Instituto Politécnico do Porto, Portugal)

clarapfcosta@gmail.com

\author{
Jaime Filipe Barbosa (Conservatório de Música de Coimbra; Academia de \\ Música de Oliveira de Azeméis, Portugal) \\ jaimefilipebarbosa@hotmail.com
}

\begin{abstract}
Resumo: Um grupo de professores de Trompete foi convidado a avaliar a performance instrumental de dois alunos. Inicialmente, a avaliação da performance instrumental dos executantes foi realizada livremente (sem referenciais teóricos ou instrumentos específicos) e posteriormente baseada na Escala de Registo da Execução Musical, a qual foi construída com base na teoria de Espiral de Desenvolvimento Musical (SWANWICK, 1988). Pretendeu-se efetuar um contraste entre as avaliações efetuadas pelos professores de Trompete, baseadas na Escala de Registo da Execução Musical (COSTA e BARBOSA, 2010) e as avaliações livremente produzidas pelos mesmos (sem referenciais). Quando se coloca em confronto as duas formas de avaliação é possível constatar inconsistências nas avaliações dos professores a respeito da performance instrumental dos alunos. Adicionalmente, é possível concluir que os professores de Trompete recorrem maioritariamente apenas a duas das dimensões da crítica musical: Materiais e Expressão, considerados os estágios situados no nível mais básico da Teoria Espiral.
\end{abstract}

Palavras-Chave: Avaliação; performance musical; Teoria Espiral de Desenvolvimento Musical de Swanwick; dimensões da crítica musical descritas por SWANWICK e TILLMAN

\section{The assessment of trumpet's instrumental performance by teachers: issues and challenges}

\begin{abstract}
A group of Trumpet's teachers was invited to assess the instrumental performance of two students. Initially, the evaluation of the performance of the two students was held freely (without theoretical frameworks or specific instruments) and then based on the Scale of Evaluation of Musical Execution, which was based on Swanwick's theory. The main objective of this research is to contrast the assessments done by Trumpet's teachers, based on Scale of Evaluation of the Musical Execution (COSTA e BARBOSA, 2010), with the free assessments (without references) carried out by the same group of teachers. By comparing the two forms of evaluation, we verify the inconsistency of the assessments and judgments in respect to the performance of the students. Additionally, our results show that Trumpet's teachers' evaluation of the students' instrumental performance is mostly focused on two dimensions: materials and expression, which are stages at the most basic levels of the Spiral Theory.
\end{abstract}

Keywords: Evaluation; musical performance; Swanwick's Spiral Theory of the Musical Development; dimensions of musical evaluation used by SWANWICK e TILLMAN

\section{Teoria Espiral de Desenvolvimento Musical: contributos para a avaliação da performance musical}

Ao nível do Ensino Especializado da Música, a avaliação, assumindo um papel importantíssimo no processo educativo, afigura-se como uma tarefa de grande delicadeza devido à natureza específica da matéria em questão. 
Entre os professores ligados à música é aceite que avaliar determinada performance musical é uma tarefa difícil, uma vez que se trata de uma manifestação artística, suscetível de diferentes interpretações decorrentes de vivências musicais e pessoais distintas. Efetivamente, ainda persiste a ideia de que a avaliação em artes não pode ser objetiva por se tratar de uma área que envolve a criatividade.

Uma das maiores dificuldades apontadas pela literatura na avaliação da música é a elaboração de critérios válidos e confiáveis para avaliar. Estabelecer uma lista do que deve (ou não) ser avaliado numa performance é uma tarefa quase impossível. Todavia, o professor deve "definir claramente o que vai ser mensurado; definir claramente as regras e os critérios para caraterizar o que vai ser avaliado, ser o mais consistente possível; usar uma aparelhagem que, na medida do possível, não prejudique as atividades normais da classe" (ASMUS, 1999, p.22).

A ausência de critérios objetivos pode tornar a avaliação do fazer musical numa tarefa demasiado subjetiva ou até arbitrária com evidentes prejuízos para o processo de ensino-aprendizagem. Esta subjetividade, mais presente no reconhecimento das qualidades musicais do que na definição das mesmas, faz com que os julgamentos daqueles que avaliam a performance musical dos alunos sejam muitas vezes inconsistentes. Mas, como acrescenta SWANWICK, não se pode continuar a justificar disparidades de julgamento atribuindo-lhes um caráter de subjetividade impenetrável. "Esta inegável componente de subjetividade inerente à experiência artística não nos isenta da necessidade de explicitarmos as bases desses julgamentos" (1994, p.102-111).

Autores como ELLIOTT (1995), JOHNSON (1997), HARGREAVES (1996), SLOBODA (1994), SWANWICK (1994), SWANWICK e TILLMAN (1986), entre outros, têm desenvolvido trabalhos científicos de grande impacto na educação musical. Destacamos nesta investigação a Teoria Espiral de Desenvolvimento Musical de SWANWICK e TILLMAN (1988) dado constituir-se como um referencial valioso para o processo de ensino-aprendizagem da música e uma mais valia para avaliação da performance instrumental.

$\mathrm{Na}$ sua prática profissional, ao analisar os currículos dos cursos oficiais de música ingleses, SWANWICK deparou-se com algumas questões relacionadas com a estrutura dos cursos, com os programas e com os critérios de avaliação, que lhe pareciam pouco coerentes ou até sem fundamento. Na tentativa de encontrar soluções para as referidas questões, desenvolveu uma teoria capaz de explicar o desenvolvimento da compreensão musical.

SWANWICK começou por propor, em 1979, o processo de aprendizagem baseado num modelo que em português foi traduzido por modelo "T.E.C.L.A.". Trata-se de uma abordagem transversal do estudo da música que consiste em trabalhar os conteúdos da aprendizagem musical de forma integral e não fragmentada, isto é, a partir das diferentes disciplinas.

Dessa forma, para garantir uma boa educação musical o professor devia, no entender de Swanwick, estar atento a todas as dimensões e não dar prioridade, 
nem desprezar qualquer dos elementos resumidos na sigla "T.E.C.L.A": TTécnica (manipulação do instrumento, notação simbólica, audição); E Execução (tocar, cantar); C - Composição (criação, improvisação); L Literatura (história da música); $\mathbf{A}$ - Apreciação (reconhecimento de estilos/forma/tonalidade/graus).

Tendo como premissa que a aprendizagem musical deve obedecer a etapas sucessivas, correspondentes ao nível de amadurecimento psicológico do indivíduo, SWANWICK e TILLMAN (1986) fizeram a monitorização do progresso desse conhecimento, estudando um grupo de alunos pertencentes à faixa etária entre os 3 e os 14/15 anos, oriundos de diversos grupos étnicos e culturais. Durante quatro anos, SWANWICK e TILLMAN realizaram gravações de composições feitas pelas crianças, num total de 745 composições de uma amostra de 48 estudantes.

Após extensa análise qualitativa efetuada às composições dos alunos, começaram a emergir padrões analíticos, revelando uma sequência de mudanças qualitativas correspondentes a uma progressiva consciência dos mesmos em relação às dimensões do conhecimento e experiência musical.

O parâmetro de análise utilizado foi a composição que, em relação à execução e à apreciação musical, permite ao aluno, segundo SWANWICK, maior liberdade sobre julgamentos e decisões musicais, tais como os relacionados com andamento, maneira de produzir os sons (articulação, dinâmica) e formar frases musicais.

Na Teoria Espiral de Desenvolvimento Musical podemos reconhecer a influência direta do trabalho de PIAGET, sobretudo da sua Teoria de Desenvolvimento Cognitivo. O próprio SWANWICK refere no seu livro "Teaching Music Musically" (1999) que a ideia de estágios cumulativos é essencialmente piagetiana. SWANWICK entende o desenvolvimento como um processo contínuo e cumulativo que ocorre em estágios numa perspetiva de evolução de um menor para um maior equilíbrio.

A Teoria Espiral apresentado por SWANWICK e TILLMAN em 1986, posteriormente expandida por SWANWICK $(1988,1994)$, representa a forma de compreender o desenvolvimento musical com base na noção de um desenvolvimento sequencial comum à maioria dos indivíduos. Para representar a sua teoria, SWANWICK e TILLMAN elaboraram um esquema em forma de espiral, através da qual pretendem mostrar os níveis de desenvolvimento musical, relacionados com a idade das crianças "compositoras" estudadas . Esta espiral desenvolve-se em quatro patamares (ou camadas) correspondentes às dimensões da crítica musical, cada uma delas dividida em dois modos (ou fases).

Para os autores, o processo de desenvolvimento musical ocorre de forma sequenciada e cumulativa através de quatro estágios ou modos (camadas ou patamares) representativos das dimensões do conhecimento musical denominados de Materiais, Expressão, Forma e Valor. A análise perpassa essas dimensões, indo da sensibilidade e do controle do material sonoro para o caráter 
expressivo e para as relações estruturais até ao reconhecimento do valor da experiência.

O estágio Materiais encontra-se presente nas crianças até aos quatro anos, sensivelmente, e é caraterizado pela consciência e pelo controle sobre os materiais sonoros, demonstrado pela distinção de timbres, níveis de intensidades, alturas, durações e pelo controlo técnico sobre instrumentos e vozes.

O estágio Expressão, que ocorre na faixa etária dos cinco aos nove anos, é caraterizado pela consciência e pelo controle do caráter expressivo, evidenciado pelo clima ou atmosfera, pelo gesto musical e pelo sentido de movimento sugerido pelo contorno da frase musical.

No estágio Forma, típico de sujeitos que se situam entre os dez e os catorze anos, o indivíduo atinge a consciência e o controle da forma e estilo musicais, manifestados nas relações entre os gestos musicais, quando os mesmos são repetidos, transformados, contrastados ou relacionados com determinada época ou estilo.

Por fim, o estágio Valor ocorre a partir dos catorze/quinze anos e é caraterizado pela apreciação da música, de forma pessoal ou cultural, demonstrada pela autonomia, pela avaliação crítica independente e por um compromisso sistemático com a música, fortemente sustentado por idiomas musicais específicos.

Cada estágio é dividido em duas fases ou modos que correspondem à natureza dialética da experiência musical polarizada nos dois lados do Espiral: o esquerdo, que representa a dimensão pessoal, idiossincrática, experimentada pelo indivíduo; e o direito, que diz respeito às convenções do fazer musical socialmente aceite.

Cada modo representa uma mudança tanto quantitativa como qualitativa relativamente ao anterior. Os autores do modelo apresentam oito modos sequenciados, hierárquica e cumulativamente: o Sensorial e o Manipulativo referentes ao estágio Materiais; o Pessoal e o Vernacular contemplados no estágio Expressão; o Especulativo e Idiomático integrados no estágio Forma; o Simbólico e o Sistemático referentes ao estágio Valor.

Mais concretamente, as transformações operadas no indivíduo passam de uma fase inicial de experimentação sonora (sensorial) para um controle manipulativo. Com a aquisição das habilidades técnicas, a expressão musical torna-se possível, ao princípio de forma espontânea (pessoal) e posteriormente de forma mais convencional, com os hábitos globalmente adotados de frase e sequência (vernacular). Estas convenções são posteriormente assimiladas como forma musical, inicialmente como especulação (especulativo) e mais tarde em estilos e idiomas específicos (idiomático). Além desses, existe a possibilidade do valor simbólico para o indivíduo e o compromisso musical sistemático. 
Segundo SWANWICK (1988) a opção pelo uso da Teoria Espiral como metáfora deve-se ao facto de esta proporcionar uma melhor visualização do movimento/fluxo operado: cíclico, cumulativo e oscilatório. O processo cumulativo pressupõe que o indivíduo que se encontra num determinado estágio, necessariamente, deve ter os estágios anteriores perfeitamente desenvolvidos. A caraterística cíclica diz respeito à necessidade da sequência da Espiral ser ativada novamente a cada encontro com a música; esta caraterística é válida tanto para um aluno a iniciar como para um músico experiente, que percorre a Espiral muito rapidamente. A terceira característica, o movimento pendular/oscilatório do lado esquerdo para o lado direito da Espiral, aponta para a polaridade existente entre os dois lados, ou seja, para a motivação pessoal e para as convenções culturais musicais, respetivamente.

No entender de SWANWICK e RUNFOLA (2002), a Teoria Espiral oferece várias implicações para o ensino da música. Destacamos aqui três dessas implicações. Em primeiro lugar, a teoria pode constituir-se como uma estratégia para o desenvolvimento do currículo em termos gerais. Desde o pré-escolar até ao ensino secundário, os currículos e as atividades escolares deveriam centrarse nos estágios e modos de desenvolvimento musical correspondentes à idade dos alunos.

Em segundo lugar, desta teoria é possível fazer derivações quanto ao papel do professor na promoção do desenvolvimento musical do aluno. Quando o professor propõe uma nova atividade ou introduz processos ou ideias musicais diferentes, é importante que tenha em mente que, a cada nova experiência musical, a sequência da Espiral deve ser reativada. O professor, ao avaliar em que ponto da Espiral o aluno se encontra, poderá conduzi-lo sempre no sentido de procurar, no próximo estádio ou modo, a sequência para o seu desenvolvimento.

Em terceiro lugar, outra implicação pedagógica do Modelo Espiral de SWANWICK diz respeito à utilização dos critérios derivados do modelo para a avaliação do fazer musical, com versões adaptadas para cada uma das modalidades: composição, execução (performance) e apreciação. SWANWICK (1994) apresenta os critérios de avaliação da performance musical por categorias ordenadas que descrevem a essência da experiência musical, contemplando a articulação dos elementos do discurso musical mencionados (FRANÇA, 2000).

Diversos estudos (SWANWICK, 1994; STAVRIDES, 1995; FRANÇA, 1998; ANDRADE, 2001; TOURINHO, 2001) encontraram evidências que suportam a validade dos critérios de avaliação de SWANWICK.

Segue-se a descrição sumária dos Critérios para Avaliação da Performance Musical (SWANWICK, 1994) segundo a Teoria Espiral de Desenvolvimento Musical de SWANWICK e TILLMAN (1986):

Sensorial - performance é errática e inconsistente. O fluxo é instável e as variações do colorido sonoro e da intensidade não parecem ter significação expressiva nem estrutural. Manipulativo - é demonstrado algum grau de controlo através de um andamento estável e pela consistência na repetição de 
padrões (motivos). O domínio do instrumento é a prioridade principal e não há ainda evidência de contorno expressivo ou organização estrutural. Pessoal - a expressividade é evidenciada pela escolha consciente do andamento e níveis de intensidade, mas a impressão geral é de uma performance impulsiva e não planeada, faltando organização estrutural. Vernacular - a performance é fluente e convencionalmente expressiva. Padrões melódicos e rítmicos são repetidos de maneira semelhante e a interpretação é previsível. Especulativo - a performance é expressiva e segura e contém alguns toques de imaginação. A dinâmica e o fraseado são deliberadamente controlados ou modificados com o objetivo de salientar as relações estruturais da obra. Idiomático - Percebe-se uma nítida noção de estilo e uma caracterização expressiva baseada em tradições musicais claramente identificáveis. Controle técnico, expressivo e estrutural é demonstrado de forma consistente. Simbólico - a performance demonstra segurança técnica e é estilisticamente convincente. Há refinamento de detalhes expressivos e estruturais e um sentimento de compromisso pessoal do intérprete com a música. Sistemático - o domínio técnico está totalmente ao serviço da comunicação musical. Forma e expressão fundem-se gerando um resultado - um verdadeiro depoimento musical - coerente e personalizado. Novos insights musicais são explorados de forma sistemática e imaginativa.

Segundo SWANWICK (1994) a Teoria Espiral pretende iluminar - e não substituir - a componente subjetiva inerente à avaliação da experiência musical. Em última instância, pode tornar mais explícitas as bases da avaliação sem entrar em conflito com julgamentos intuitivos.

\section{Metodologia}

Utilizamos neste estudo o método de análise de produtos (SWANWICK, 1994), recorrendo à gravação da performance de alunos de Trompete $^{1}$, em duas obras musicais distintas e à sua posterior avaliação por professores do ensino especializado da música (Trompete), a partir de duas metodologias de avaliação distintas: avaliação livre (sem instrumentos e critérios de avaliação específicos) e uma avaliação formal, utilizando uma Escala de avaliação construída para o efeito, a qual se baseou em critérios da crítica musical de SWANWICK (1994).

\subsection{Questões do estudo}

Com este estudo pretendemos:

i) Perceber em que medida a utilização dos Critérios para Avaliação da Performance Musical de SWANWICK podem contribuir para uniformizar a forma de avaliar dos professores de Trompete relativamente à performance instrumental dos alunos;

ii) Averiguar em que medida as avaliações dos professores de Trompete exploram e contemplam as diferentes dimensões da crítica musical consideradas por SWANWICK e TILLMAN (1986)

iii) Contrastar as avaliações efetuadas pelos professores de Trompete baseadas nas dimensões da crítica musical descritas por SWANWICK e TILLMAN (1986) na sua Teoria Espiral com as avaliações livres (sem referenciais) efetuadas pelos mesmos a respeito da performance musical dos alunos.

\subsection{Amostra}


A amostra deste estudo é constituída por nove professores de sete escolas do Ensino Especializado da Música das zonas norte e centro do país. Apenas foram selecionados professores que lecionam a disciplina de Trompete por corresponder ao instrumento executado na performance dos alunos. Todos os sujeitos são do sexo masculino e têm idades compreendidas entre os vinte e três e os trinta e cinco anos. As habilitações académicas dos sujeitos situam-se entre o bacharelato e a licenciatura. Foram recolhidas 36 avaliações produzidas pelos 9 professores de trompete (cada professor avaliou os dois alunos que executaram duas peças musicais diferentes, a partir de duas metodologias de avaliação distintas usadas) a respeito da performance instrumental dos alunos.

\subsection{Instrumentos}

Neste estudo foram utilizados dois instrumentos.

-Relatório de Avaliação Qualitativa da Execução Musical (COSTA e BARBOSA, 2010). Neste relatório, os professores de Trompete podem livremente (na ausência de linhas ou referenciais orientadores) efetuar as suas apreciações acerca dos desempenhos dos alunos.

- Escala de Registo da Execução Musical (COSTA e BARBOSA, 2010). Esta escala foi concebida a partir dos Critérios para Avaliação da Performance Musical de SWANWICK (1994).A escala utilizada é constituída por 26 parâmetros de avaliação. Os parâmetros 1 - Postura (Corporal/Embocadura), 2 - Controle da respiração e 3 - Emissão sonora, situam-se no modo Sensorial do estágio Materiais. Através destes parâmetros é possível avaliar a capacidade para explorar o contato com a Trompete. Os parâmetros 4 - Ataque, 5 Articulação, 6 - Extensão/Tecitura, 7 - Afinação e 8 - Sonoridade, situam-se no modo Manipulativo do estágio Materiais. Estes parâmetros permitem avaliar a capacidade para manusear e controlar tecnicamente a Trompete. Os parâmetros 9 - Respeito pelo texto musical, 10 - Escolha do andamento, 11 - Estabilidade rítmica e 12 - Uso de diferentes intensidades, situam-se no modo Pessoal do estágio Expressão e permitem avaliar a capacidade para tocar com sentido expressivo e bom gosto musical. Os parâmetros 13 - Organização rítmica das frases, 14 - Organização melódica das frases, 15 - Fluência do discurso musical e 16 - Expressividade do discurso musical, situam-se no modo Vernacular do estágio Expressão e possibilitam avaliar o sentido expressivo do aluno de acordo com as convenções adotadas pela linguagem musical. Os parâmetros 17 Segurança do discurso musical, 18 - Controle e variedade de dinâmicas e 19 Compreensão da estrutura da obra, situam-se no modo Especulativo do estádio Forma e através destes é possível avaliar a capacidade para controlar os detalhes expressivos de forma a salientar a estrutura da obra. Os parâmetros 20 - Noção de estilo musical e 21 - Identificação com as opções estéticas da época, situam-se no modo Idiomático do estágio Forma e avaliam a capacidade para tocar de acordo com as opções técnicas, estéticas e estruturais que definem o estilo e a época da obra. Os parâmetros 22 - Refinamento dos detalhes expressivos e estruturais e 23 - Compromisso entre interpretação e estilo/forma musical, situam-se no modo Simbólico do estádio Valor. Através destes parâmetros procuramos avaliar o aperfeiçoamento do que foi exigido nos parâmetros anteriores conjugado com a capacidade do aluno para conferir um cunho pessoal à obra. Finalmente, os parâmetros 24 - Domínio técnico de excelência, 25 - Capacidade de comunicar e transmitir emoções e 26 - 
Capacidade para orientar a própria evolução, situam-se no modo Sistemático do estádio Valor e possibilitam-nos a avaliação da mestria técnica do aluno, a sua capacidade para comunicar e transmitir emoções e autonomia para encontrar o seu próprio rumo musical.

Para cada um dos parâmetros a avaliar é utilizada uma escala de quatro pontos: insuficiente, suficiente, bom e excelente.

Antes da aplicação da escala foi efetuada uma reflexão falada levada a cabo por dois especialistas na área com vista a eliminar itens com problemas de elaboração.

\subsection{Procedimento}

Efetuamos, em primeiro lugar, o registo em vídeo da execução de duas obras musicais - Concerto de J. B. G. NERUDA (10 Andamento) e "Suite" de E. BAUDRIER $^{3}$ - por dois alunos de Trompete (Aluno A e B). Estes vídeos destinam-se a ser visionados pelos nove professores de trompete que depois avaliarão as execuções musicais dos alunos. As duas obras foram executadas com acompanhamento ao piano, realizado pelo mesmo pianista, e as gravações foram realizadas numa situação equivalente a uma prova ou audição.

Os instrumentos foram administrados aos inquiridos pela seguinte ordem: os Relatórios de Avaliação Qualitativa da Execução Musical foram preenchidos em primeiro lugar e após o visionamento/audição dos respetivos vídeos. As Escalas de Registo da Execução Musical foram preenchidas por último, com um intervalo de dois dias em relação à "avaliação livre".

Cada docente de trompete foi convidado a avaliar as duas performances de cada aluno a partir de duas metodologias de recolha de dados distintas, pelo que no final obtivemos 36 "produtos" que foram objeto de análise.

\section{Discussão dos resultados}

Situaremos a apresentação e análise dos resultados tomando como eixos: a. A abrangência das dimensões da crítica musical usadas pelos professores para classificar a performance musical dos alunos; $\boldsymbol{b}$. A consistência das avaliações dos professores de música a respeito da performance musical dos alunos

\section{a. A abrangência das dimensões da crítica musical usadas pelos professores para classificar a performance musical dos alunos}

Com base na análise dos Relatórios de Avaliação Qualitativa da Execução Musical, podemos constatar que os inquiridos fizeram 54 referências ao estágio Materiais (75\%); 39 referências ao estágio Expressão (54,17\%). O estágio Forma foi mencionado por 22 vezes (30,56\%) e apenas um dos sujeitos fez uma única referência ao estágio Valor (Ex.1). 


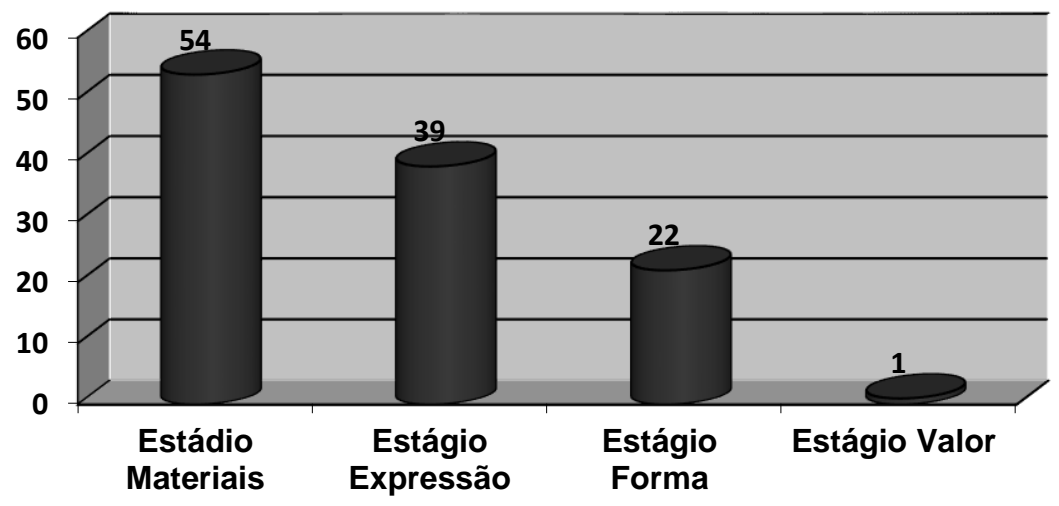

Ex.1 - Gráfico relativo ao número de referências feitas pelos 9 professores a cada estádio da Teoria Espiral na avaliação livre.

Como se pode analisar com base nos dados do Ex.1, os inquiridos exploraram de forma assimétrica as diferentes dimensões da crítica musical. Os sujeitos atribuíram grande peso à dimensão dos Materiais, um peso considerável à dimensão da Expressão, uma valorização relativamente mais reduzida à dimensão da Forma. Apenas um professor considera a dimensão do Valor. Perante estes resultados poder-se-á dizer que, à luz da teoria de SWANWICK, estas apreciações não refletem a preocupação dos professores em explorarem o desenvolvimento musical dos alunos na sua plenitude.

Observando os dados do Ex.2 podemos verificar que, considerando a avaliação efetuada pela totalidade dos inquiridos relativamente à execução dos dois alunos nas duas obras com base na Escala de Registo da Performance Musical, o valor médio mais alto (média=2,7) situa-se no estágio Materiais enquanto o valor médio mais baixo encontra-se no estágio Valor (média=2,4). Observa-se uma ligeira diminuição dos valores médios à medida que se vai subindo de estágio ao longo da espiral de desenvolvimento musical.

\begin{tabular}{|ccccc|}
\hline Estágios & Média & Desvio-padrão & Mínimo & Máximo \\
\hline Materiais & 2,7 & 0,35 & 2,08 & 3,27 \\
Expressão & 2,6 & 0,29 & 2 & 2,88 \\
Forma & 2,5 & 0,39 & 1,75 & 3,1 \\
Valor & 2,4 & 0,31 & 1,9 & 2,75 \\
\hline
\end{tabular}

Ex.2 - Tabela relativa aos dados de estatística descritiva referentes à avaliação efetuada pela totalidade dos professores considerando a execução dos dois alunos nas duas obras

Se compararmos as avaliações efetuadas pelos inquiridos através dos Relatórios de Avaliação Qualitativa da Execução Musical com as avaliações efetuadas através das Escalas de Registo da Performance Musical, e sabendo que ambas se reportam às mesmas performances, podemos afirmar que, de uma forma geral, não há coerência por parte dos inquiridos nas avaliações. Nas avaliações efetuadas na presença dos critérios de avaliação de SWANWICK, os sujeitos avaliaram os dois alunos tendo em conta os quatro estágios de desenvolvimento musical, enquanto na ausência desses mesmos critérios, as avaliações fizeramse em referência a três estágios e de forma desigual. 
As médias totais por estágio relativas às avaliações efetuadas pelos nove inquiridos através da Escala de Registo da Performance Musical, diminuem à medida que subimos na espiral e o estágio Valor foi o menos valorizado pelos sujeitos nas quatro execuções, mas também não deixa de ser verdade que os alunos foram avaliados positivamente em todos os estágios, incluindo o de Valor, daí podermos concluir ser contraditório a ideia desse estágio não ter sido considerado pelos sujeitos nos Relatórios de Avaliação Qualitativa da Execução Musical, assim como a menor importância atribuída ao estágio Forma.

\section{b. A consistência das avaliações dos professores de música a respeito da performance musical dos alunos}

A partir das avaliações efetuadas pelos inquiridos com base na Escala de Registo da Execução Musical, podemos constatar uma significativa variabilidade nessas mesmas avaliações (Ex.3). Os professores não apresentam concordância quanto à apreciação que efetuaram acerca da execução do aluno A na obra de NERUDA, existindo maior acordo nos julgamentos efetuados relativamente ao primeiro estágio.

\begin{tabular}{|l|c|c|c|c|c|c|c|c|c|}
\hline \multirow{4}{*}{ ESTÁGIOS } & \multicolumn{7}{|c|}{ SUJEITOS } & (nove professores de trompete) \\
\cline { 2 - 11 } & $\begin{array}{c}\text { Prof. } \\
14\end{array}$ & $\begin{array}{c}\text { Prof. } \\
2\end{array}$ & $\begin{array}{c}\text { Prof. } \\
3\end{array}$ & $\begin{array}{c}\text { Prof. } \\
4\end{array}$ & $\begin{array}{c}\text { Prof. } \\
5\end{array}$ & $\begin{array}{c}\text { Prof. } \\
6\end{array}$ & $\begin{array}{c}\text { Prof. } \\
7\end{array}$ & $\begin{array}{c}\text { Prof. } \\
8\end{array}$ & $\begin{array}{c}\text { Prof. } \\
9\end{array}$ \\
\cline { 2 - 11 } & Média & Média & Média & Média & Média & Média & Média & Média & Média \\
\hline Materiais & 2,74 & 2,4 & 3,3 & 2,7 & 2,84 & 3,37 & 2,2 & 2,84 & 2,7 \\
\hline Expressão & 2,75 & 2,75 & 3,13 & 2,75 & 2,88 & 3 & 1,88 & 3 & 2,25 \\
\hline Forma & 3,42 & 2,34 & 2,84 & 2,34 & 2,17 & 3 & 1,75 & 2,75 & 2,17 \\
\hline Valor & 2,67 & 2 & 3,17 & 2,59 & 2,84 & 3 & 2 & 2,42 & 1,59 \\
\hline
\end{tabular}

Ex.3 - Tabela relativa às médias referentes à avaliação da execução do aluno $A$ da obra Concerto J.B.G de NERUDA

Em relação à execução da Suite de BAUDRIER pelo aluno $A$, os inquiridos não apresentam avaliações concordantes. Note-se 0 desacordo quanto aos parâmetros de avaliação contemplados no estádio Valor, avaliados por um inquirido com Insuficiente e por outro como Bom (Ex.4).

\begin{tabular}{|c|c|c|c|c|c|c|c|c|c|}
\hline & \multicolumn{8}{|c|}{ SUJEITOS (nove professores de trompete) } \\
\cline { 2 - 11 } & $\begin{array}{c}\text { Prof. } \\
1\end{array}$ & $\begin{array}{c}\text { Prof. } \\
2\end{array}$ & $\begin{array}{c}\text { Prof. } \\
3\end{array}$ & $\begin{array}{c}\text { Prof. } \\
4\end{array}$ & $\begin{array}{c}\text { Prof. } \\
5\end{array}$ & $\begin{array}{c}\text { Prof. } \\
6\end{array}$ & $\begin{array}{c}\text { Prof. } \\
7\end{array}$ & $\begin{array}{c}\text { Prof. } \\
8\end{array}$ & $\begin{array}{c}\text { Prof. } \\
9\end{array}$ \\
\cline { 2 - 11 } ESTÁGIOS & Média & Média & Média & Média & Média & Média & Média & Média & Média \\
\hline Materiais & 3,17 & 2,2 & 3,37 & 2,8 & 2,84 & 3,37 & 2,3 & 2,2 & 2,8 \\
\hline Expressão & 2,63 & 2 & 2,88 & 2,13 & 2,88 & 3,38 & 2,25 & 2,13 & 3 \\
\hline Forma & 3,25 & 2,17 & 3 & 2,67 & 2 & 3,34 & 1,42 & 2 & 3,34 \\
\hline Valor & 2,84 & 1,59 & 3,17 & 2,59 & 2,84 & 3 & 2,09 & 2,17 & 2,67 \\
\hline
\end{tabular}

Ex.4 -Tabela relativa às médias referentes à avaliação da execução do aluno A da obra Suite de E. BAUDRIER. 
A mesma variabilidade de julgamentos dos inquiridos encontra-se presente na execução do Concerto de NERUDA. Nos estádios Materiais, Forma e Valor a execução do mesmo aluno é apreciada pelos professores inquiridos ora como abaixo do suficiente ora como de nível bom (Ex.5).

\begin{tabular}{|c|c|c|c|c|c|c|c|c|c|}
\hline \multirow{2}{*}{ ESTÁDIOS } & \multicolumn{7}{|c|}{ SUJEITOS (nove professores de trompete) } \\
\cline { 2 - 11 } & Prof. & Prof. & Prof. & Prof. & Prof. & Prof. & Prof. & $\begin{array}{c}\text { Prof. } \\
8\end{array}$ & $\begin{array}{c}\text { Prof. } \\
9\end{array}$ \\
\cline { 2 - 11 } & $\begin{array}{c}2 \\
\text { Média }\end{array}$ & Média & Média & Média & Média & Média & Média & Média & Média \\
\hline Materiais & 2,6 & 2,9 & 2,94 & 2,17 & 2,84 & 1,74 & 2,24 & 3,1 & 3,37 \\
\hline Expressão & 3 & 2,75 & 2,38 & 2,25 & 2,63 & 2,5 & 2,13 & 3,13 & 3,13 \\
\hline Forma & 3 & 2,34 & 2 & 2,17 & 2,17 & 2,67 & 1,75 & 3 & 3 \\
\hline Valor & 3,09 & 2,42 & 2 & 2 & 2,67 & 2 & 1,59 & 3,17 & 2,84 \\
\hline
\end{tabular}

Ex.5 - Tabela relativa às médias referentes à execução da execução do aluno $B$ da obra Concerto J.B.G de NERUDA.

Os dados do Ex.6 evidenciam discordância na avaliação dos docentes quanto à execução da Suite de BAUDRIER pelo aluno B.

\begin{tabular}{|c|c|c|c|c|c|c|c|c|c|}
\hline & \multicolumn{8}{|c|}{ SUJEITOS (nove professores de trompete) } \\
\cline { 2 - 11 } & $\begin{array}{c}\text { Prof. } \\
1\end{array}$ & $\begin{array}{c}\text { Prof. } \\
2\end{array}$ & $\begin{array}{c}\text { Prof. } \\
3\end{array}$ & $\begin{array}{c}\text { Prof. } \\
4\end{array}$ & $\begin{array}{c}\text { Prof. } \\
5\end{array}$ & $\begin{array}{c}\text { Prof. } \\
6\end{array}$ & $\begin{array}{c}\text { Prof. } \\
7\end{array}$ & $\begin{array}{c}\text { Prof. } \\
8\end{array}$ & $\begin{array}{c}\text { Prof. } \\
9\end{array}$ \\
\cline { 2 - 11 } ESTÁGIOS & Média & Média & Média & Média & Média & Média & Média & Média & Média \\
\hline Materiais & 2,6 & 2,9 & 3,1 & 2,34 & 2,84 & 1,74 & 1,9 & 3,1 & 3,37 \\
\hline Expressão & 3 & 2,63 & 2,25 & 2,38 & 2,63 & 2,13 & 2 & 3,13 & 3,13 \\
\hline Forma & 2,84 & 2,34 & 2,17 & 2,84 & 2,17 & 1,34 & 1,84 & 3 & 3 \\
\hline Valor & 2,67 & 2 & 2,17 & 2 & 2,67 & 1,88 & 1,59 & 3,17 & 2,67 \\
\hline
\end{tabular}

Ex.6 -Tabela relativa às médias referentes à avaliação da execução do aluno B da obra Suite de E. BAUDRIER.

Estes resultados são consistentes com o estudo de FRANÇA (2000) segundo o qual os examinadores chegam a avaliações diferentes relativamente à mesma performance. Acreditamos que esta diferença de perspetiva se deve, por um lado, às diferentes conceções ou escolas dos inquiridos, que os levam a valorizar de forma diferente determinados aspetos, e, por outro lado, à forte componente de subjetividade presente nas realizações artísticas, que permite interpretações diferentes da mesma obra.

Procuraremos agora discutir a análise da variabilidade das respostas dadas pelos sujeitos a partir do Relatório de Avaliação Qualitativa da Execução Musical.

Sobre a execução do Concerto de NERUDA ( $1^{\circ}$ andamento) pelo aluno $\mathrm{A}$, um dos sujeitos comentou: "Classifico esta execução de muito bom nível: ao nível de estilo, expressividade, ornamentos, técnica...", enquanto outro escreveu: 
"Tecnicamente, tem algumas falhas que prejudicam a sua prestação, nomeadamente a falta de controlo da coluna de ar...".

Relativamente à execução da Suite de BAUDRIER pelo aluno $A$, um dos professores referiu: "Ao nível da realização técnica o aluno esteve em bom plano. Também fez uma correta interpretação da articulação...”, enquanto outro salientou: "... o principal problema é o contraste dinâmico exigido e o aluno não o interpretou... no $2^{\circ}$ andamento a articulação deveria ser diferente".

No que respeita à execução do Concerto de NERUDA pelo aluno $B$, um dos docentes salientou: "Classifico-a mesmo de brilhante: boa sonoridade, expressividade, boa flexibilidade, agudos bons, técnica bastante apurada, ornamentos bem feitos. Quanto à resistência, respiração, fraseado, ritmo e concentração posso classificá-la de excelente", enquanto outro escreveu: “... alguns problemas de afinação. A interpretação está demasiado precipitada, provocando também algumas oscilações na pulsação".

Sobre a execução do aluno B da Suite de BAUDRIER um dos sujeitos referiu: "O aluno mostra ser um aluno muito equilibrado, com uma sonoridade bonita e controlada na sua extensão. Mostrou um bom desempenho musical", enquanto outro docente escreveu: "... revela alguns problemas no registo agudo do instrumento, além de alguns problemas de afinação. Algumas passagens não estão devidamente controladas".

Estes julgamentos exemplificam que a mesma performance pode suscitar em diferentes avaliadores juízos antagónicos e ajudam a explicar as diferenças encontradas nos resultados das avaliações efetuadas através da Escala de Registo da Performance Musical.

Se é possível que dois professores emitam juízos tão diferentes relativamente à mesma execução, talvez esses professores não estejam realmente a fazer uma apreciação crítica objetiva dessa execução mas a manifestarem inconscientemente a sua preferência por determinada forma de tocar. A ideia que a diferença entre a apreciação crítica de uma performance e a preferência por determinada forma de tocar deve ser definida previamente com clareza, porque a primeira é mais objetiva e a segunda mais subjetiva, é defendida por TOURINHO e OLIVEIRA (2003).

A questão da variabilidade das apreciações pode ser igualmente discutida a partir do item critérios de avaliação da execução musical, aspeto avaliado no questionário ${ }^{5}$ de caracterização da perceção dos professores de trompete acerca da avaliação.

Colocando em contraste as avaliações efetuadas por cada sujeito através do Relatório de Avaliação Qualitativa da Execução Musical com as respostas ao item acima referido, onde é pedido aos sujeitos os critérios de avaliação que utilizam, verificou-se que na maioria dos casos não há concordância entre estas situações. Ou seja, alguns inquiridos apresentaram uma lista de critérios de avaliação que dizem utilizar na sua atividade diária, mas que não corresponde às avaliações que efetuaram quer com base no Relatório quer na Escala.

A constatação de que os critérios de avaliação apresentados pelos inquiridos não se encontrarem espelhados nas avaliações efetuadas permite chegar a duas conclusões: i) frequentemente, os professores não avaliam os alunos de acordo com as próprias conceções teóricas. Trata-se de uma separação 
evidente entre a teoria e a prática que já tinha sido constatado por SANTOS (2003), ii) os professores de música sentem dificuldades quando têm de justificar por palavras determinado juízo de carácter musical, o que vem ao encontro das opiniões de autores como SWANWICK (1994), FRANÇA (2000) e TOURINHO (2001).

\section{Conclusão}

A avaliação das práticas musicais é um processo complexo. Como salienta SWANWICK (1999) a "avaliação engloba desde a constante - ou mesmo instantânea - verificação do resultado atingido, realizada pelo próprio músico ou outrem, até procedimentos formais de avaliação nos exames regulares de instrumento" (p.69-74).

Os resultados evidenciaram uma elevada variabilidade nas avaliações produzidas pelos professores deste estudo. O grau de variabilidade é consideravelmente maior quando os professores de Trompete avaliam a performance musical dos executantes sem apoio de critérios pré-definidos. Contudo, também se verificaram inconsistências e disparidades na avaliação dos professores quando estes apreciam o desempenho dos alunos a partir dos critérios operacionalizados com base na Teoria Espiral de SWANWICK.

Os resultados encontrados neste estudo colocam em evidência a velha questão, tão debatida no âmbito das ciências da educação: a lacuna epistemológica que separa o discurso musical do discurso concetual (JOHNSON, 1997 citado por FRANÇA, 2004). Nem sempre é fácil mobilizar referenciais e grelhas de análise teóricas que guiem e orientem a nossa praxis profissional. $O$ fosso entre teoria $e$ prática permanece ainda em aberto. Ou poderão os resultados do nosso estudo querer evidenciar que a atitude adotada pelos professores de trompete, caraterizada pela menor valorização de critérios de avaliação formais e objetivos, corresponde a uma tentativa de evitar comprometer a integridade e o carater holístico da experiência musical, a qual não deve ser fragmentada pela aplicação de critérios formais? Independentemente das razões que possam explicar a inconsistência dos dados encontrados, os resultados desta investigação revelam a necessidade de desenvolver critérios objetivos, claros e inequívocos de avaliação da experiência musical. A este respeito, tal como tem sido reconhecido na comunidade científica, os critérios propostos por SWANWICK (1994) parecem produzir uma razoável confiança nos professores aquando da avaliação do ensino e da aprendizagem da mesma (DEL BEN, 2003), constituindo assim uma excelente ferramenta a usar no processo avaliativo (FRANÇA e SWANWICK, 2002).

Verificamos ainda que os professores quando solicitados a avaliar o nível de desenvolvimento musical dos alunos apenas consideram duas das dimensões da crítica musical, a dimensão dos Materiais e Expressão. Os estágios Forma e Valor, tidos como o pináculo da compreensão da música como forma de discurso simbólico, são substancialmente menos considerados pelos sujeitos da amostra na avaliação. À semelhança do estudo de FRANÇA encontramos, grosso modo, nos resultados deste estudo uma conceção de avaliação da experiência musical que enfatiza sobremaneira a "dimensão técnica em detrimento do resultado musical como um todo" (2004, p.35). Uma das 
explicações para estes resultados poderá ser encontrada, na opinião de FRANÇA (2004, p.35), na ideia de que os estágios mais elevados da Teoria Espiral "integram aspetos que escapam à linguagem objetiva-o indizível."

No entanto, ainda a este propósito, SWANWICK (1999) não deixa de lembrar que os professores "devem reconhecer a complexidade da experiência musical. Uma atividade tão rica não pode ser reduzida a uma ou duas dimensões. (...) A natureza de qualquer atividade artística parece obrigar à identificação de várias dimensões diferentes " e à tentativa de classificar cada uma delas."(COSTA, 2010, p.98)

Estamos, pois, em crer que a avaliação da performance musical dos alunos é um assunto que merece atenção urgente por parte de todos aqueles que se dedicam ao ensino destas matérias, apesar de reconhecermos que, muitas vezes, o "nível de articulação simbólica e estética numa performance ultrapassa os limites da expressão da linguagem verbal" (FRANÇA, 2004, p.35). Contudo, como reconhece KEITH SWANWICK "é importante encontrar um vocabulário significativo comum, bem como critérios que façam sentido para toda a gente", sendo necessário que os professores de música tomem consciência da importância "(...) de padrões explícitos, de uma linguagem partilhada da crítica musical” (1999, p.72).

\section{Referências}

ANDRADE, Margareth. A avaliação em execução musical. Estudo sobre critérios utilizados por regentes de grupos corais escolares. Paraná: UFPR, 2001.

ASMUS, Edward. Music Assessment Concepts. Music Educators Journal, v.86, n.2, 1999, p.1924.

COSTA, Maria Manuela. O valor da música na educação na perspetiva de Keith Swanwick. Lisboa: Instituto de Educação da Universidade de Lisboa, 2010 (Dissertação de Mestrado).

COSTA, Clara; BARBOSA, Jaime. Avaliação na Música: questões e dificuldades. Fafe: Escola Superior de Educação de Fafe, 2010 (Tese do Curso de Formação Complementar em Orientação Educativa).

DEL BEN, Luciana. Avaliação da aprendizagem musical dos alunos: reflexões a partir das conceções de três professoras de música do ensino fundamental. In: HENTSCHKE e SOUZA (Orgs). Avaliação em Música: reflexões e práticas. São Paulo: Editora Moderna, 2003, p.29-40.

ELLIOTT, David. Music Matters, a new philosophy of music education. New York: Oxford University Press, 1995.

FRANÇA, Cecilia Cavalieri. Composing, performing and audience-listening as symmetrical indicators of musical understanding. University of London Institute of Education,1998 (Tese de Doutoramento, PhD).

FRANÇA, Cecília Cavalieri. Possibilidades de aplicação do modelo espiral de desenvolvimento musical como critério de avaliação no vestibular da escola de música da UFMG. Opus, Belo Horizonte: UFMG, v.7, 2000b, www.musica.ufmg.br/anppom/opus. Acesso em: 3 de abril,2012.

FRANCA, Cecília Cavalieri. Dizer o indizível: considerações sobre a avaliação da performance instrumental de vestibulandos e graduandos em música. PER Musi, n.10, 2004, p.31-48.

FRANÇA, Cecilia Cavalieri; SWANWICK, Keith. Composição, apreciação e performance na educação musical: teoria, pesquisa e prática. Em Pauta, v 13, no 21, 2002, p.5-41.

HARGREAVES, David. The developmental psychology of music: Scope and aims. In: G. SPRUCE (Ed). Teaching Music. London: Routledge, 1996.

JOHNSON, Peter. Performance as Experience: the problem of assessment criteria. British Journal of Music Education, v.14, n.3, 1997, p.271-282. 
SANTOS, Cynthia. Avaliação da Execução Musical: A Concepção Teórico-prática dos Professores de Piano. In: HENTSCHKE, L. e SOUZA, J. (Orgs), Avaliação em música: reflexões e práticas. São Paulo: Moderna. 2003. cap 3, p.41-50.

SLOBODA, John. Music performance: expression and the development of excellence. In: R. AIELLO (Ed.), Musical perceptions New York: Oxford University Press,1994, p.152-172.

STAVRIDES, Michael. The Interaction of Audience-Listening and Composing: A Study in Cyprus Schools, Unpublished PhD, University of London, Institute of Education,1995.

SWANWICK, Keith. Music Mind and Education. London: Routledge,1988. Routledge, 1994.

.Musical Knowledge. Intuition analysis and music education. London:

.Teaching Music Musically. New York: Routledge, 2012.

SWANWICK, Keith; TILLMAN, June. The sequence of musical development: a study of children's composition. British Journal of Music Education, v. 3, n.3, 1986, p.305-339.

SWANWICK, Keith; RUNFOLA, Maria. Developmental characteristics of music learners. In R. COLWELL E C. RICHARDSON (Eds.). The new handbook of research on music teaching and learning. MENC. Oxford: Oxford University Press, 2002, p.373-397.

TOURINHO, Cristina. Relações entre os Critérios de avaliação do professor de Violão e uma teoria de Desenvolvimento Musical. Salvador, 2001 (Tese de Doutoramento).

TOURINHO, Cristina; OLIVEIRA, Alda. Avaliação da Performance Musical. In: HENTSCHKE e. SOUZA (Orgs), Avaliação em música: reflexões e práticas. São Paulo: Moderna. 2003, p.13-28.

\section{Notas}

${ }^{1}$ As dimensões da crítica musical descritas por SWANWICK e TILLMAN correspondem aos estágios de desenvolvimento musical.

${ }^{2}$ Os dois alunos, com 17 anos de idade, frequentam o 5. Grau de Trompete e apresentam um rendimento escolar de elevado nível. De acordo com a totalidade dos docentes dos dois alunos, estes apresentam um desempenho musical homogéneo.

${ }^{3}$ As peças foram cuidadosamente escolhidas com base em pré-requisitos.

${ }^{4}$ A sigla PROF quer dizer professor.

${ }^{5}$ Nesta investigação foi utilizado ainda um Questionário sobre as Perceções dos Docentes relativamente à Avaliação na Música. Um das questões ou itens incluídos neste instrumento relaciona-se com os critérios de avaliação usados pelos docentes quando têm que apreciar a execução musical dos alunos.

Maria Clara Pereira Fernandes Costa é licenciada em Psicologia pela Universidade do Minho. Em 2000 apresentou a tese de Mestrado na mesma instituição na área de Psicologia Escolar. Atualmente prepara candidatura ao doutoramento em Psicologia na Universidade de Aveiro. Desde 1999 tem exercido funções como docente do ensino superior, tendo colaborado com a Universidade do Minho e a Universidade Católica Atualmente exerce a atividade docente na Escola Superior de Educação de Fafe e na Escola Superior de Tecnologias de Saúde do Instituto Politécnico do Porto. Tem orientado teses e projetos de investigação subordinados à análise do processo de ensino-aprendizagem numa vertente psicológica. Tem publicado na área da Psicologia da Educação.

Jaime Filipe Barbosa realizou os seus estudos musicais no Conservatório de Música do Porto, onde concluiu em 1993 o Curso Completo de Trompete (Exp. Pedagógica de 1971). Mais recentemente, em 2007, concluiu a licenciatura em Orientação Educativa na Escola Superior de Educação de Fafe. Enquanto Trompetista colabora com instituições como a Orquestra Nacional do Porto e a Orquestra Filarmonia das Beiras, entre outras, e apresenta-se regularmente integrado em formações de música de câmara. É, desde 1995, professor da disciplina de Trompete no Conservatório de Música de Coimbra e na Academia de Música de Oliveira de Azeméis. 